Aus MssMed:

Augsburg, UB, cod. II.1.2 31 , a. 1428, fol. 184ra-vb. Zusammen mit $O$ mors quam amara est memoria tua. Gemeinsamer Titel für beide Texte: Qualiter mors cuidam apparuit.

Aus In principio:

Kremnica (Kremnitz), Farská Knižnica, Cx III (Sopko 164), 15. Jh., fol. 203ra-205ra.

\title{
R41. Anonymus Spiritualis
}

\section{Responsio ad Abbreviaturam Communitatis}

Rep.: Mohan 43*.

Studie: Kapitel 3.4.2., 3.4.5.

Prolog: Incipit: Beatus vir qui non abiit in consilio impiorum et in via etc. [Ps 1, 1] Evangelico viro triplex imponitur malignitas fugienda... Explicit.... ante articulos autem praemittunt prologum istum.

Incipit: Relaxationis defensio: Beatus qui intelligit super egenum et pauperem, Psalmus [Ps 40, 2]. Praecedit actus meritorius ut succedat...

Explicit: Reducat igitur eos misericors Deus ad paupertatis intelligentiam et amorem et dignetur caecitatis tam palpabiles effugare tenebras vitae suae operibus radiosis.

Autor: Der Autor wird nicht genannt, es handelt sich aber offensichtlich um einen Spiritualen. Mohan schlägt Ubertino da Casale vor, allerdings ohne Begründung.

Datierung: Dieses Werk entstand in der Zeit des Konzils von Vienne (16.10.1311-6.5.1312) oder kurz vorher als Teil der Polemik zwischen Franziskaner-Konventualen und Spiritualen. Für die Konventualen schrieb Richard von Conington seinen Tractatus contra opiniones Petri Johannis Olivi (Ed. Heysse, „Fr. Richardi“"). Von diesem Traktat edierten die Konventualen eine Zusammenfassung, die Abbreviatura communitatis (Ed. Heysse, „Fr. Richardi“, 66-69), in der sie ihren Standpunkt in vierzehn Artikeln festhielten. Auf diese Schrift reagiert das hier behandelte Werk.

Inhalt: Die vierzehn Artikel der Abbreviatura werden wörtlich zitiert unter der Bezeichnung Relaxationis defensio. Auf jeden Artikel folgt die Erwiderung unter dem Titel Regulae perfectio. Bis auf diese formale Aufteilung fehlen jegliche Elemente eines Dialogs (Anreden, direkte Fragen, 